Pecvnia, 7 (2008), pp. 125-148

\title{
Análisis DAFO de los Picos de Europa de León
}

Recibido: Septiembre 2008 Aceptado: Mayo 2009

\author{
Julio Lago Rodríguez \\ jclagr@unileon.es \\ Universidad de León \\ Fac. de Ciencias Económicas y Empresariales \\ Campus de Vegazana, $\mathrm{s} / \mathrm{n}$ \\ 24071 León (España) \\ Lorenzo Sevilla Gallego \\ larry.al@terra.es \\ 24915 Soto de Valdeón (León)
}

El presente estudio realiza un análisis estratégico de los Picos de Europa de León, un enclave montañoso perteneciente a la Cordillera Cantábrica que forma parte de la Red Estatal de Parques Nacionales. Se identifican debilidades, amenazas, fortalezas y oportunidades de un territorio en fase de transformación socioeconómica. La confección de la matriz DAFO sintetiza las principales conclusiones, a la vez que sirve de guía para definir las líneas de actuación que pueden aportar un futuro más prometedor a tan singular espacio natural protegido.

Palabras clave: Análisis estratégico de recursos naturales. Desarrollo rural. Picos de Europa. Economía leonesa.
The following study carries out a strategic analysis of Picos de Europa, a mountainous area in the Cantabrica Mountain Range, which forms part of the Spanish Sate Park Net. Stregths, weaknesses, opportunities and threats are identified in this place still subject to a socioeconomic transformation. The SWOT report summarizes the main conclusions, as well as it can be used as a guide to define future plans thay may contribute to offer a promising future for such a singular natural protected area.

Key words: Strategic analysis of natural resources. Country development. Picos de Europa. Leonese economy. 


\section{INTRODUCCIÓN}

El artículo aborda el análisis de un espacio natural protegido, los Picos de Europa de León, mediante la aplicación de técnicas que habitualmente se manejan en el ámbito de la moderna teoría de la administración de empresas. Esta pretensión analítica podría parecer, en principio, extraña o rara ya que la realidad objeto de estudio no es un exponente de la actividad económica en sentido estricto, sino un lugar geográfico repartido entre León, Asturias y Cantabria que atesora cualidades naturales de singular atractivo.

No en vano la zona seleccionada ha sido distinguida con la declaración de parque nacional, figura que, desde 1918, es sinónimo de máximo rango legal en materia de protección y reconocimiento de los valores ambientales en España. Sin embargo hemos considerado que los procedimientos y técnicas de análisis empresarial no están reñidos con enfoques y disciplinas ajenos a su riguroso ámbito de aplicación. Es más, pensamos que pueden ser muy útiles para diagnosticar la posición de partida de los espacios naturales protegidos con el fin de contribuir a diseñar planes de gestión conducentes a una mejora progresiva de su estatus actual. Bajo estos planteamientos, se aplican los esquemas teóricos del análisis estratégico empresarial y se utiliza la técnica DAFO como herramienta básica para sintetizar las principales conclusiones obtenidas. Su elaboración aportará un testimonio sólido para comprobar la importancia que puede desempeñar la disposición de una masa de datos bien estructurada. Una masa de datos que, sin llegar a ser plenamente exclusiva de la vertiente leonesa del macizo de los Picos de Europa, representada por los valles de Sajambre y Valdeón, servirá de apoyo para acometer un análisis estratégico particularizado de este ámbito territorial. Precisamente mueve nuestro ánimo el deseo de que este trabajo sea una primera aportación, no cerrada, tanto descriptiva como analítica, susceptible de poderse enriquecer en futuras colaboraciones.

\section{FUNDAMENTOS DE ANÁLISIS ESTRATÉGICO Y TÉCNICA}

DAFO

Como ha puesto de manifiesto la doctrina en múltiples pronunciamientos, el objetivo primordial de todo análisis estratégico 
consiste en identificar las características y rasgos esenciales de una realidad que se pretende diagnosticar. Representa, desde un plano formal y académico, la primera de las etapas, el punto de partida, de todo proceso encaminado a proponer soluciones y respuestas a una problemática específica. Constituye, en esencia, la fase que ayuda a conseguir los elementos de juicio, y más concretamente la información cualitativa necesaria para efectuar un correcto dictamen. Este conocimiento previo es común que se articule de forma bietápica al acometer un doble análisis sobre el hecho objeto de estudio. En el caso que nos concierne, un territorio de montañas y valles de sobresaliente biodiversidad y reconocida calidad paisajística que se administra bajo la figura de un parque nacional.

El primero de estos análisis, de tipo exógeno, se centraría en el estudio del entorno, entendiendo por entorno el conjunto de factores externos al espacio natural que tiene, o puede llegar a tener, una influencia directa o indirecta sobre su devenir. Su misión radica en determinar la importancia que el marco externo tiene sobre el área protegida con el fin de identificar amenazas y oportunidades que condicionan el momento presente y futuro de la misma. El segundo de los análisis, de orientación más endógena, respondería al deseo de identificar los puntos fuertes y débiles que definen el potencial intrínseco del espacio natural. Es una visión analítica más enfocada a descubrir la existencia de capacidades y recursos propios que personalizan las posibilidades de mejora de una zona geográfica con señas de identidad muy definidas, teniendo en cuenta que el parque nacional de los Picos de Europa es naturaleza de élite pero también un colectivo de personas que viven en su entorno. Esta información que proporciona el análisis estratégico es la que finalmente se sintetiza mediante la técnica o matriz DAFO, base adecuada para definir directrices y futuras líneas de actuación. La expresión DAFO es el acrónimo resultante de las palabras debilidades, amenazas, fortalezas y oportunidades, correspondientes al original anglosajón SWOT (strengths, weaknesses, opportunities y threats). El significado preciso de cada una de ellas es el que a continuación se detalla:

a) Debilidades: sinónimo de limitaciones. Se conciben como factores endógenos que actúan de manera desfavorable hacia la vertiente leonesa de los Picos de Europa.

b) Amenazas: sinónimo de peligros. Aglutina influencias negativas del entorno para el macizo montañoso objeto de análisis. 
c) Fortalezas: sinónimo de potencialidades. Identifican factores internos que impactan de manera favorable sobre Sajambre y Valdeón.

d) Oportunidades: sinónimo de posibilidades. Engloba influencias positivas del entorno para el área de montaña estudiada.

En resumen, las oportunidades y amenazas harán referencia a los aspectos externos del espacio natural. Tienen por misión recoger los influjos positivos y negativos que el entorno puede irradiar hacia el mismo. Las fortalezas y debilidades se alinearán más con la relación de factores internos o internalidades que contribuyen a dinamizar o paralizar el pulso vital de la zona protegida.

\section{ANÁLISIS DAFO DE LOS PICOS DE EUROPA DE LEÓN}

Actualmente, y como ya se ha hecho constar, el macizo de los Picos de Europea es un enclave montañoso que forma parte de la Red Estatal de Parques Nacionales. Constituyen los Picos de Europa una unidad geológica integrada, aunque con personalidad propia, en el abrupto relieve de la Cordillera Cantábrica. Su estructura la conforman tres macizos calizos: Cornión o macizo occidental (León y Asturias), Urrieles o macizo central (León y Asturias) y Andara o macizo occidental (Asturias y Cantabria). En su génesis, año 1918, el primero de los catorce declarados en España hasta el momento, su delimitación (17.076 Has.) abarcaba solamente el macizo occidental (Cornión), aportando el $75 \%$ de su primitiva extensión Asturias y el $25 \%$ restante León (terrenos del valle de Valdeón). En fechas más recientes, mayo de 1995, y por acuerdo de las Cortes Generales, esta primera configuración, vigente a lo largo de 77 años, se modifica y pasa a extenderse a todo el bloque calizo y a buena parte de su ámbito de influencia, es decir, pasa a incluirse dentro de la figura de protección los macizos de los Urrieles y Andara así como las superficies territoriales que engloban su esfera de influjo socioeconómico más directo.

Este cambio legislativo, que resalta el carácter unitario del macizo, conlleva nueva denominación y el antiguo parque nacional de la Montaña de Covadonga se rebautiza, adoptando el nombre definitivo de parque nacional de los Picos de Europa. Con el nuevo perímetro, que supone casi cuadriplicar la dimensión anterior (64.660 Has.), los dos 
municipios leoneses, Oseja de Sajambre, articulado en cinco pueblos (Oseja, Vierdes, Pío, Ribota y Soto), y Posada de Valdeón, con ocho localidades (Posada, Santa Marina, Caín, Cordiñanes, Prada, Los Llanos, Caldevilla y Soto) pasan a aportar todo su territorio y toda su población al recién creado parque nacional. De los diez ayuntamientos que hoy integran esta área protegida (Tresviso, Camaleño, Cillórigo de Liébana, Cabrales, Onís, Cangas de Onís, Amieva, Peñamellera Baja, Oseja y Posada) sólo el cántabro de Tresviso participa de la singularidad leonesa.

En la nueva fisonomía del parque nacional el protagonismo de las regiones cambia, contribuyendo León con un 38,2\%, Asturias con el $37,9 \%$ y Cantabria con el 23,7\%. Este hecho expansionista de los límites de protección marcará, sin duda, un antes y un después en el devenir y gestión de la zona, afectando de lleno a las tres funciones esenciales que desempeña todo espacio natural protegido: función ecológica o de salvaguarda ante los procesos erosivos degradantes, función social como lugar de ocio y soporte para la investigación y mejora del conocimiento científico, y por último, función económica o productiva asimilable a territorio, aunque en descenso, de aprovechamientos agrícolas y forestales. En la actual coyuntura el protagonismo es asumido por las dos primeras funciones en detrimento de la tercera que, pese a rentabilizar todavía determinados usos agropecuarios, ha perdido peso específico en el seno de la estructura económica local.

\section{DEBILIDADES}

\section{a) Crisis del modelo económico tradicional}

Desde antiguo, como ya nos hemos hecho eco en otros trabajos (Lago 2008), la base económica de los Picos de Europa ha estado protagonizada por el sector primario. El uso del suelo ha proporcionado pastos para alimentar, a diente o a siega, cabañas vacunas, ovinas y caprinas que reportan producciones cárnicas y lácteas de apreciable calidad para el autoconsumo y la venta a terceros. Sin embargo, desde hace poco más de un cuarto de siglo la solidez de esta clásica estructura económica se agrieta, presentando graves fisuras que tienen su origen en los procesos generalizados de industrialización y urbanización vividos por nuestro país, cuyos rasgos esenciales pasan por concentrar la actividad empresarial en las ciudades y en sus respectivas áreas metropolitanas. 
Se fomenta la ganadería intensiva, independizada del medio natural, en detrimento de la veterana práctica ganadera en régimen extensivo, que se caracteriza por aprovechar la riqueza de los abundantes pastizales mediante trashumancia local entre los prados de los valles y los puertos de montaña (majadas), auténticas despensas vegetales de muy alto valor nutritivo. Surge así un cambio de modelo económico donde el desarrollo del turismo y la conservación del medio ambiente pasan a figurar como principales alternativas al tradicional medio de vida pastoril.

De manera progresiva la economía de Sajambre y Valdeón se terciariza. Va perdiendo peso la economía de signo agrario en favor de una economía amparada en el sector servicios que proporciona empleos menos incómodos y con mayor consideración social que la ocupación agropecuaria. El caso de Caín de Valdeón, pueblo pastoril por excelencia, es sumamente ilustrativo. Prácticamente ha eliminado su cabaña caprina, la ganadería como actividad profesional, para apoyar su supervivencia en los empleos inducidos por el turismo y el parque nacional. A largo plazo, el impacto demográfico de este cambio en la estructura productiva de la comarca determinará la bondad de esta transición.

De manera adicional semejante reconversión de las fuentes generadoras de ingresos trae consigo consecuencias desfavorables para los valores naturales de los Picos de Europa. No aprovechar las abundantes praderías degrada el territorio, provocando una transformación negativa sobre el terreno y el paisaje picoeuropeanos que atenta contra la riqueza ambiental de tan privilegiado conjunto montañoso. El declive de la ganadería extensiva, liderada por la cabaña vacuna, facilita que el matorral invada el praderío, con la consiguiente pérdida de este recurso económico.

Así mismo, esta tendencia hacia una menor presencia ganadera socava la estructura que podría afianzar una elaboración y comercialización de alimentos cárnicos y lácteos asociada a la imagen de marca del propio espacio natural protegido. Buen ejemplo es la producción quesera de Valdeón. El afamado queso azul que se comenzó elaborando en Posada bajo el marchamo de denominación de origen ha tenido que cambiar a indicación geográfica protegida por no disponerse de suficiente materia prima (leche) en el valle. Cabe añadir que esta modificación en la procedencia de los aprovisionamientos lácteos en nada ha perjudicado a la calidad del producto, pues el saber hacer de la única empresa familiar, Queserías Picos de Europa, S.L., que fabrica desde 1989 este alimento no ha impedido que el queso azul de Valdeón haya sido distinguido en dos ocasiones, 2005 y 2007, como el primer queso de pasta 
azul de España por parte del extinto Ministerio de Agricultura, Pesca y Alimentación. Una manifestación de industria agroalimentaria bien asentada en el mercado, con porvenir, que admitiría nuevos fabricantes.

Sin embargo no puede ocultarse que la práctica ganadera no atrae en exceso a los jóvenes de la montaña, aún cuando requiere menor servidumbre y atención diaria el vacuno de carne frente al vacuno de leche. Una actitud que tímidamente se quiere empezar a invertir en Sajambre, donde una joven emprendedora de Oseja recuperará, en breve, la producción artesanal del queso de Los Beyos. Ante la condición periférica de la comarca es recomendable que los proyectos agropecuarios a implantar sean integrales o de ciclo completo. Ello significa que los promotores asuman, mediante integración vertical, las etapas básicas del proceso productivo: aprovisionamiento, industrialización, logística y comercialización parcial en el mismo ámbito geográfico productor. Es la forma de controlar el valor añadido del proceso y evitar los intermediarios. Considerando hacia donde apuntan las nuevas tendencias de los mercados ganaderos nacionales sería la estructura de negocio más idónea para asegurar un mínimo de rentabilidad económica. Por otra parte, estimular el regreso de la juventud al medio rural hace imprescindible medidas de corte político orientadas a elevar la imagen y reputación sociolaboral de la profesión ganadera. Instaurar un ciclo educativo de uno o dos años, de manera análoga a como se hace en otros oficios, sería un primer paso.

\section{b) Déficit de recursos humanos}

Sajambre y Valdeón vienen experimentando una tendencia poblacional preocupante que contribuye a fortalecer la imagen de la montaña como foco de emigración. La consulta de los datos aportados por el Instituto Nacional de Estadística para el período 1996-2007, justo desde el arranque de la nueva andadura del parque nacional, revela que la demografía ofrece un comportamiento dispar. El municipio de Posada de Valdeón mantiene su número de censados, incrementando incluso ligeramente sus habitantes al pasar de 511 a 543. Por el contrario, el municipio de Oseja de Sajambre recorta su población oficial en un $20 \%$. De 356 residentes evoluciona a 285 . No obstante, un examen más profundo de la realidad humana de ambos valles obliga a matizar el grado de representatividad de las anteriores cifras. Es sabido que los censados no son siempre los verdaderos pobladores de un territorio. No es inusual que en un ayuntamiento se empadronen personas que no fijan su 
residencia habitual en el municipio. Motivos vinculados con el disfrute de derechos cinegéticos, de permisos para la práctica de la pesca, de aprovechamientos forestales y otros afines hacen que los censos puedan variar de manera más aparente que real, ya sea manteniéndose o creciendo, caso de Posada, o disminuyendo en menor medida de la realidad, caso de Oseja.

Esta sensación es la que se percibe cuando se visita cualquiera de los dos valles fuera de la temporada veraniega. De ahí que sea preciso valorar en su justo término la información sobre población rural suministrada por las estadísticas oficiales. Su análisis detallado descubre la existencia de un grave problema de recursos humanos. Esta falta de energía demográfica, que guarda estrecha relación con el cambio del modelo económico descrito, conlleva un alto envejecimiento que penaliza las tentativas de desarrollo de la zona por falta de actores.

El territorio se desantropiza, tendiéndose a erosionar la más elemental calidad de vida en el área protegida por ser directa la correlación entre número de habitantes y la disposición de servicios básicos en materia de sanidad, educación, ocio, comercio y transportes. Vierdes, pueblo asentado en el valle de Sajambre, ha sido la primera víctima. El último censo elaborado en 2007 le otorga una población de ocho personas. Su población real, permanente, queda reducida en la práctica a un solo vecino. Va camino de engrosar la esquela rural, arrastrando esta negativa dinámica demográfica la continuidad de los usos y tradiciones rurales más señeras del espacio montañés.

Por efecto de la despoblación caen en desuso multitud de costumbres que, de una manera lenta pero inexorable, vacían y despersonalizan la más íntima esencia del territorio (García 1999). El despoblamiento se agrava con la inexistencia de una política que facilite el fortalecimiento del censo a través de la incorporación de nuevos vecinos. La carencia de un verdadero mercado de vivienda propicia una situación paradójica en la que más de la mitad de los inmuebles se encuentran deshabitados o sin uso, mientras que es casi imposible acceder a los mismos en régimen de alquiler. Los precios de compra son desproporcionadamente altos, quizá debido a unas supuestas expectativas especulativas que no se ven contrarrestadas con una acción de gobierno local que favorezca el asentamiento de nuevos habitantes, ya que, a diferencia de otros núcleos de la montaña leonesa, existe una demanda real que no puede ser satisfecha, como se demuestra con los problemas 
que tienen los maestros y otros funcionarios y contratados que van llegando al parque nacional con el deseo de fijar su residencia.

\section{c) Falta de apoyo local a las figuras de protección}

Cuando han transcurrido trece años desde su nueva configuración, el parque nacional no ha sido objeto de una valoración positiva por todos los sectores implicados. El sentimiento de aceptación social dista de ser unánime, hasta el punto de que consolidar el mismo entre los habitantes de Sajambre y Valdeón es todavía una asignatura pendiente, un escollo no superado. Un número no pequeño de vecinos no creen en los beneficios que reporta vivir dentro un espacio natural protegido, llegando incluso a concebir el parque como una idea contraria al progreso. Se piensa que la protección de la naturaleza es un freno para el desarrollo. Si esto ocurre, tal y como se expone en Casas (1998), es porque han sido más patentes las restricciones, prohibiciones y limitaciones que las ayudas, incentivos e indemnizaciones. Está fallando, o no es plenamente eficaz, el plan de compensaciones socioeconómicas a las poblaciones afectadas.

La actual situación de desencanto es así porque en múltiples aspectos el espacio natural protegido sólo ha existido sobre el papel y no en la práctica, causando un alto grado de malestar y frustración entre los habitantes. Los lugareños desconfían, y en ocasiones con motivo para ello, pues no ven materializarse con la celeridad debida el anuncio de inversiones y la llegada de recursos que se traduzcan de forma inmediata en mejoras sociales para los pobladores del entorno. La Administración, quizás, no se ha sabido ganar la confianza de los locales. No ha sabido, tal vez, disipar los recelos y las posturas iniciales de rechazo ante un deseo institucional de proteger y conservar naturaleza habitada.

Picos de Europa es un claro exponente de simbiosis hombrenaturaleza. De ahí que una figura de parque nacional, como forma que es de organizar un territorio, no pueda obviar este hecho si de verdad se pretende impulsar un modelo de relaciones que apueste por un implantar un desarrollo sostenible (producir conservando) en la zona. Esta peculiaridad ha provocado fracturas de la convivencia ciudadana que no son nada aconsejables por enrarecer el marco de relaciones fluidas a establecer entre Administración y residentes del espacio. La humanización del territorio objeto de conservación es todo un reto para los comportamientos de los organismos públicos, ya que en buen número de 
ocasiones será una constante en la gestión del parque nacional pilotar el consenso de intereses contrapuestos con los habitantes de los pueblos.

\section{AMENAZAS}

\section{Deficiencias en la gestión del espacio natural}

La falta de consenso y la proliferación de planteamientos enfrentados que emanan de las diferentes instituciones públicas, léase administración central (Ministerio de Medio Ambiente y Medio Rural y Marino), autonómica (Junta de Castilla y León) y local (Diputación de León, ayuntamientos y juntas vecinales), están llevando al territorio protegido a una situación compleja que ha alimentado, en más de lo debido, disputas y agrias polémicas en los poco más de trece años de su nueva etapa.

Son las consecuencias derivadas de la irrupción o entrada en escena de la política. La posibilidad o no de practicar la caza y la pesca, la corta de leña, el deseo, materializado en la nueva Ley $5 / 2007$ de Parques Nacionales, de excluir la presencia de núcleos habitados dentro del perímetro del parque (crisis de los límites), el diseño urbanístico de los pueblos o la construcción de determinados tipos de infraestructuras (funiculares, pistas forestales, aparcamientos, etc.) son, entre otros, los matices que en mayor medida sobresalen en la nómina de aspectos que actúan como fuente de conflicto. Ejemplo claro para ilustrar este enredo administrativo es la doble normativa de protección (parque nacional y parque regional) que actualmente recae sobre la vertiente leonesa del macizo (Sajambre y Valdeón).

La mayor burocracia y la no coincidencia del tenor literal de las diferentes normativas contribuyen en muy poco o en nada a favorecer el necesario clima de entendimiento y concordia que requiere la gestión de un área geográfica de estas características. Hablamos del único parque nacional de España que divide su superficie entre varias comunidades autónomas. Los inconvenientes de esta maraña administrativa se han visto agravados coyunturalmente por la interinidad que ha caracterizado los puestos de dirección del espacio natural, los avatares de la aprobación de un elemento clave en la ordenación y vida del parque como es el Plan Rector de Uso y Gestión (PRUG) o la demora que acumula la puesta en marcha de los planes de desarrollo sostenible (PDS) para cada uno de los municipios afectados. 
Además, desde 2004 esta complejidad de la situación administrativa se ha visto ampliada con un nuevo frente. Una reciente sentencia del Tribunal Constitucional obliga a ceder a las comunidades autónomas la gestión de los parques nacionales (Torres 2005). En el caso de Picos el traspaso acumula un notable retraso al no ponerse de acuerdo las cuatro administraciones implicadas sobre el modelo de organización a practicar, existiendo el riesgo real de que la gestión no sea unitaria, con toda la carga de excentricidad política que ello pueda suponer. Por mala administración del territorio, tan peculiares cumbres de la Cordillera Cantábrica van camino de ser un tesoro inútil para la economía leonesa, pues no se logran rentabilizar de una manera cierta y sostenible sus innegables posibilidades de desarrollo.

\section{Peligro de sobreexplotación turística}

Distinguir un territorio con la categoría de parque nacional incrementa un interés de visita que, en el caso de los Picos de Europa, ha sido un fiel reflejo de esta premisa, hasta el punto de ser el parque nacional más frecuentado de la Península, viéndose sólo superado por los parques nacionales canarios del Teide y Timanfaya. Esta cifra global de visitantes, que sobrepasa 1.700 .000 turistas anuales, presenta comportamientos muy desiguales, pues más de la mitad $(61 \%)$ son entradas localizadas en Asturias. La zona cántabra contabiliza en torno a un $29 \%$, mientras que en la vertiente leonesa se cifra en un escaso 10\%, acaparando buena parte de este porcentaje el Valle de Valdeón.

En un breve apunte, tan notables diferencias numéricas no son ajenas, entre otros motivos, a la débil cuando no inexistente promoción institucional de los dos valles leoneses de Picos ${ }^{1}$. Habla por sí sólo que en la carretera nacional 625, trayecto Mansilla-Cistierna-Riaño, principal vía de entrada al macizo por León, no exista prácticamente ninguna señalización vial ni paneles informativos sobre el itinerario y las distancias kilométricas a Sajambre y Valdeón. Un hecho harto incomprensible cuando Picos es una de las zonas más visitadas de la geografía leonesa. Al margen de estándares numéricos, lo cierto es que semejante movimiento de personas

\footnotetext{
Excepción sería la reciente visita, finales de agosto de 2008, que a título personal y como practicante del montañismo, realizó al Valle de Valdeón el Presidente del Gobierno José Luis Rodríguez Zapatero. La estancia fue grabada para difundirse días después en un programa de televisión de ámbito nacional.
} 
obliga a definir un tipo de turismo que pasa por conjugar tres aspectos interrelacionados y a priori contrapuestos (Urz 1995): la capacidad turística de carga que puede acoger el área protegida sin que sufra daños irreversibles en su integridad, el umbral de actividad empresarial inducida por el turismo que puede mantener un cierto nivel demográfico en la zona y el grado de conservación del espacio físico que asegura el atractivo de sus valores ambientales. El razonamiento, a priori, es fácil. A mayor afluencia de visitantes, mayor actividad económica, y a su vez, mayores visos de vitalidad poblacional. Las pegas surgen en lo relativo a la conservación del espacio natural, pues cabe pensar que un entorno degradado no captaría la atención de un colectivo ciudadano demandante de tiempo de ocio y descanso en contacto con la naturaleza.

La degradación del ecosistema, e incluso la incomodidad que provoca la turistización excesiva del espacio natural, puede terminar restando eficacia a la economía que su conocimiento y disfrute genera. De ahí la importancia de no infravalorar este aspecto en el entramado orientado a determinar el techo de visitantes que conjuga vitalidad poblacional sin deterioro del hábitat. Ha de estar presente la mesura en la explotación de los recursos naturales. En el terreno de lo práctico la realidad de la parte leonesa de Picos de Europa no es comparable a la situación cántabra y asturiana. Los datos sobre entrada de visitantes proporcionadas por el propio parque nacional así lo ratifican.

Puede afirmarse que el peligro de sobreexplotación turística, por lo que conlleva de presión humana sobre el medio, apreciable en el hervidero de gente que se concentra en la temporada estival en el enclave de los Lagos de Covadonga (Asturias) o en el eje Potes-Fuente Dé (Cantabria), no se ha detectado aún en ninguno de los dos valles leoneses salvo en el tramo de carretera que discurre entre Posada de Valdeón y Caín, que es parte de la ruta del Cares. En su estado actual de desarrollo el turismo de los Picos en León, en su intento de ser una alternativa económica válida para frenar la despoblación, está pendiente de madurar. En Sajambre es muy débil el aprovechamiento de sus recursos naturales, disponiendo de margen de maniobra para impulsar, sin deterioro del medio ambiente, un mayor nivel de actividad empresarial que pueda tener impacto positivo sobre la demografía del valle.

Respecto a Valdeón, pese a ser mayor la infraestructura hotelera disponible y el uso del medio por parte de los visitantes, la eficacia socioeconómica del turismo no está dando todos los frutos apetecidos por tratarse de un turismo de gravedad (Sevilla 1997). Es un 
fenómeno espontáneo, un turismo de inercia que cae por su propio peso ante la belleza y el encanto que encierra el lugar. No viene inducido por acciones institucionales coordinadas de gestión del territorio. Esta clase de turismo ha tenido, la mayoría de las veces, una contestación insuficiente por parte de los hosteleros, hasta el punto de que buen número de los establecimientos basan su negocio en dar únicamente satisfacción a las necesidades primarias que el visitante demanda, es decir, alojamiento y manutención.

No se estila incrementar las rentas generadas por la afluencia de visitantes con iniciativas complementarias y paralelas enfocadas a crear una imagen de marca, léase promoción conjunta de ambos valles, oferta de turismo activo, divulgación del patrimonio cultural, gastronomía con productos de la zona, estética de los locales acorde con el entorno montañés, entre otras actuaciones, que bien podrían conseguir un mayor efecto económico a través de la prolongación de la estancia, muy centrada en la realización de la ruta del río Cares.

Precisamente esta condición más embrionaria del turismo en ambos valles permitiría, si se planifica con un mínimo de racionalidad, evitar crecimientos anárquicos y desordenados, a la vez que ayudaría a compaginar los tres vértices del triángulo antes citado. Se plantea eludir situaciones de saturación advertidas en Asturias y Cantabria que pueden resultar contraproducentes a medio y largo plazo. No se trata de desprestigiar la actividad turística ni tampoco postular que la naturaleza protegida sea aislada de todo contacto exterior. Se invoca un desarrollo turístico equilibrado, sostenible, de calidad, que evite caer en la mala impresión y en los errores advertidos en las visitas que se realizan a determinados lugares de las otras dos vertientes. Ahí puede residir un hecho diferencial para los Picos leoneses. Puede ser el planteamiento que mejor combine bienestar de los residentes y conservación del espacio natural.

En este propósito puede desempeñar un papel relevante, e incluso innovador, el fomento de un turismo de signo académico, es decir, promover la presencia de personas por razones vinculadas a la función social de los espacios protegidos. Sajambre y Valdeón son un marco muy idóneo para desarrollar foros de estudio, investigación y debate de temas que tengan como telón de fondo el análisis y conocimiento en profundidad de la naturaleza. Precisamente a este objetivo ha respondido el Aula Picos de Europa promovida desde el año 1999 por parte de la Universidad de León (Lago 2007). 
Déficit de educación ambiental por parte de los visitantes

En la actualidad los parques nacionales de España reciben más de diez millones de visitas anuales, lo que en estos momentos ya supone una cifra considerable de circulación de personas por su interior. Picos de Europa, como ya se ha hecho constar, figura en los puestos de cabeza de este ranking. Al margen ahora de consideraciones de índole socioeconómicas, este dato obliga a conectar con el rastro o la huella que pueden dejar los humanos a su paso por un espacio natural, pues toda visita al mismo genera residuos. Pese a los avances conseguidos, el grado cívico que los ciudadanos demuestran hacia la naturaleza dista todavía de alcanzar los niveles deseados.

La carencia de una cultura de cuidado y respeto hacia los ecosistemas es lo que actúa como señal de alarma ante una afluencia turística intensa. La aparición de basuras y desperdicios de toda clase que se abandonan en los pueblos, caminos y veredas o en los propios márgenes de los ríos, por no decir la destrucción de vegetación y patrimonio forestal, son realidades evidentes de la amenaza que supone para la integridad y atractivo de un espacio natural protegido la falta de una mínima educación ambiental por parte de los ciudadanos que se acercan a conocerlos. Precisamente este peligro hace reflexionar en ocasiones sobre la conveniencia de descubrir, de promocionar, enclaves naturales de privilegiada belleza. Un riesgo que sólo se combate inculcando respeto por el medioambiente desde la más temprana educación escolar. El reto pasa por conocer sin degradar. En el caso concreto de la vertiente leonesa de Picos es en el trayecto Posada-Caín-Desfiladero del Cares donde más perceptibles llegan a ser las huellas negativas de las 135.000 personas que, según los datos promedio del Organismo Autónomo Parques Nacionales, visitan anualmente Sajambre y Valdeón.

\section{Uso impropio de la denominación Picos de Europa}

Grave está siendo la confusión terminológica creada con el término «Picos de Europa». Su empleo, desde 1995, por parte de la Junta de Castilla y León para designar espacios naturales (vertiente leonesa) que no tienen ni un solo metro cuadrado en el conjunto del macizo, caso del denominado Parque Regional Picos de Europa en Castilla y León, formado por Sajambre, Valdeón y las montañas de Riaño y Mampodre, está contribuyendo a deslocalizar la ubicación exacta de los enclaves geográficos. 
Las montañas de Riaño y Mampodre poseen entidad suficiente para seducir sin necesidad de adjetivos terminológicos prestados de cara a resaltar sus atractivos ambientales y paisajísticos, que sin lugar a dudas los tienen. Incluso, y por razones de una falta de consolidación del parque nacional, surgen conductas oportunistas que manejan, de manera directa o indirecta, la marca Picos de Europa a su antojo sin haber contribuido a la conservación de tan emblemáticas montañas en idéntica manera a como lo hacen los verdaderos pobladores del macizo. Este hecho, que no deja de ser una evidencia más de las deficiencias ya apuntadas en materia de gestión del espacio natural, tendría que corregirse.

Sería todo un gesto de enmienda y buena voluntad política rectificar el uso equivocado de un nombre que se está utilizando para designar un espacio protegido que abarca, por poner unos sencillos ejemplos, hasta las tierras de Boñar y Puebla de Lillo, dos entornos de montaña que, aún teniendo un alto interés natural, distan más de 50 kilómetros de los verdaderos Picos de Europa. Cualquier persona conocedora de la montaña leonesa sabe que se trata de zonas distintas. Abundantes son los estudios botánicos, geológicos y geográficos que acreditan semejante realidad. Por lógica, el gentilicio Picos de Europa se debería emplear exclusivamente para referirse a los valles de Sajambre y Valdeón. El uso de esta semántica impropia en poco está favoreciendo la identificación territorial del macizo con León. Son decisiones políticas que no ayudan a contrarrestar el extendido pensamiento ciudadano que asocia los Picos de Europa sólo con Asturias y Cantabria.

\section{FORTALEZAS}

\section{Calidad del patrimonio natural}

Múltiples son los aspectos que resaltan los valores y las cualidades biogeográficas de los Picos de Europa, las montañas del norte. A su condición de excepcionalidad geológica caliza se unen la existencia de áreas altimontanas relevantes que hacen del macizo un genuino representante de una amplia gama de especies vegetales y faunísticas. La lista de atributos es larga sobresaliendo, entre otros, la importancia mundial de su modelado glaciar y kárstico, la belleza de sus bosques, su condición de Zona de Especial Protección para las Aves (ZEPA), de Reserva de la Biosfera y el hecho de ser el único parque nacional de España con presencia de lobo, oso pardo y salmón. Esta integración de rasgos permite que la zona ofrezca un paisaje de muchos quilates, de excepcional fisonomía 
y visualidad que ha sido alabada y reconocida por múltiples foros y organismos nacionales e internacionales.

En la vertiente leonesa acreditan semejante condición parajes como Vegabaño y sus hayedos multicolores, pues no en vano Sajambre y Valdeón son un auténtico paraíso forestal, la senda del Arcediano, la ruta del Cares, el desfiladero de los Beyos o la contemplación de cumbres con estatura superior a 2.600 metros, la altitud más alta de toda la Cordillera Cantábrica, sin caer en el olvido Santa Marina de Valdeón, el pueblo más elevado (1.118 metros) de todos los Picos. En este capital natural residen, sin duda, las bazas más sólidas y consistentes del atractivo del macizo. Conservarlo y mantenerlo en el mejor estado posible resulta obligado, dado que se presenta como una exigencia en aras de asegurar que siga siendo una fortaleza o punto fuerte del territorio. De su buen estado dependerá que Sajambre y Valdeón, y por extensión, el conjunto de los tres macizos, sigan desempeñando un papel destacado dentro del panorama turístico norteño articulado en torno al icono de la España Verde. Una marca turística que promociona un recorrido por el norte peninsular a través de unas montañas, la Cordillera Cantábrica, que asoman al mar. A esta proyección contribuirá, sin duda, la avanzada intención de la Unesco de declarar la totalidad de la Cordillera, desde Ancares hasta Picos de Europa, como territorio reserva de la biosfera.

\section{Único Parque Nacional Peninsular del Noroeste de España}

La división del territorio español por cuadrantes pone de manifiesto que Picos de Europa, por su ubicación geográfica, es lugar estratégico para conocimiento y divulgación de entornos naturales de alta calidad. En un radio no inferior a 400 kilómetros es el único espacio protegido peninsular que permite el contacto con naturaleza de élite a un amplio espectro de ciudadanos procedentes de regiones sin superficie en los Picos, caso de Galicia, País Vasco, Castilla y Madrid. En este sentido, el no rivalizar por proximidad con otros parques nacionales eleva su potencial como foco de interés para difundir ecosistemas de gran valor ecológico y cultural en la franja noroeste del país, estando muy bien posicionado como punto de destino para conocer sistemas representativos de la región eurosiberiana ligados al bosque atlántico. Dentro de la Península Ibérica las áreas naturales protegidas más cercanas a Picos de Europa con rango de parque nacional se asientan, como se comprueba en el cuado adjunto, en Pirineos, con dos parques nacionales, Ordesa y 
Monte Perdido en Huesca, y Aiguestortes i Estany de San Maurici en Lérida, y La Mancha, también con dos parques nacionales, Cabañeros en Toledo y Ciudad Real, y las Tablas de Daimiel en Ciudad Real.

Cuadro 1. Red Española de Parques Nacionales

\begin{tabular}{|l|c|l|}
\hline PARQUE NACIONAL & FECHA & LOCALIZACIÓN \\
\hline Ordesa y Monte Perdido & 1918 & Huesca \\
\hline Caldera de Taburiente & 1954 & La Palma \\
\hline Teide & 1954 & Tenerife \\
\hline Aigües Tortes y Estany Sant Maurici & 1955 & Lleida \\
\hline Doñana & 1969 & Huelva y Sevilla \\
\hline Tablas de Daimiel & 1973 & Ciudad Real \\
\hline Timanfaya & 1974 & Lanzarote \\
\hline Garajonay & 1981 & Gomera \\
\hline Archipiélago de Cabrera & 1991 & Isla de Cabrera \\
\hline Cabañeros & 1995 & Ciudad Real y Toledo \\
\hline Picos de Europa & 1995 & León, Asturias y Cantabria \\
\hline Sierra Nevada & 1999 & Granada y Almería \\
\hline Islas Atlánticas & 2002 & Galicia \\
\hline Monfragüe & 2007 & Cáceres \\
\hline
\end{tabular}

Fuente: Ministerio de Medio Ambiente y Medio Rural y Marino.

\section{Disposición de atractivos no vinculados al medio ambiente}

La vertiente leonesa de los Picos de Europa atesora más elementos de valor que los propios recursos ambientales. Al margen de ofrecer una naturaleza sobresaliente dispone de manifestaciones del patrimonio cultural que pueden potenciar el aprovechamiento turístico del territorio. La presencia de hórreos y de otras construcciones de la arquitectura popular, caso de molinos, fuentes, lavaderos y paneras, entre otros, unida a la disposición de edificios singulares con un pasado histórico relevante, bien puede complementar el atractivo de las visitas que por razones de medio ambiente se realizan al entorno del macizo. Destacables son, en este sentido, las escuelas centenarias de Soto de Sajambre, inauguradas en 1907 y en funcionamiento hasta principios de los años ochenta, momento a partir del cual se clausuran por falta de alumnos. Fueron todo un hito educativo de la época cuyo papel supera lo meramente arquitectónico. Promovidas y financiadas, en buena medida, por un oriundo del valle, Félix de Martino, cuya biografía ya es un reclamo cultural de primer orden, sorprenden por la cantidad y calidad de los 
materiales y equipamientos didácticos con que estaba dotada, impropios del tiempo y de un pueblo tan remoto de la montaña leonesa. Biblioteca, utensilios de laboratorio, láminas ilustradas, aparatos de medición, entre otros recursos disponibles para la enseñanza, conforman hoy un legado histórico digno de conocer. Pese al potencial turístico que encierra son muy recientes las únicas actuaciones de rehabilitación, financiadas por el parque nacional, dirigidas a su puesta en valor. El proyecto de convertirlas en museo acumula un notorio retraso por la desidia y desinterés de las administraciones, miopes ante la disposición de un recurso cultural de tanta valía. De no menos atractivo son los hórreos de Valdeón.

Nuevo ejemplo del pasado, de la historia, como potencial germen de riqueza. Algunas de estas construcciones típicas de la alta montaña datan de hace más de 400 años, encontrándose en la actualidad en un aceptable grado de conservación. Su divulgación como elemento configurador del modo de vida de los montañeses e incluso del propio paisaje enriquecería, sin duda, la imagen turística de la vertiente leonesa de Picos. No en vano desde 1979 tienen la declaración de monumento histórico-artístico de carácter nacional. De igual relevancia resulta el conocimiento del Chorco de los Lobos, recinto cilíndrico de piedra con empalizada de madera y fines cinegéticos, o la ermita de Nuestra Señora de Corona, enclave legendario evocador de la historia de la Reconquista.

La relación es amplia. Las manifestaciones etnográficas citadas son sólo una muestra del riquísimo patrimonio no vinculado al medio ambiente que disponen ambos valles. Su oferta como reclamo turístico es la asignatura pendiente. No serían pocos los interesados en un conocimiento más pormenorizado de este otro paisaje picoeuropeano. El turismo cultural, como fórmula de ocupación del ocio, es un fenómeno social en auge.

\section{OPORTUNIDADES}

\section{Menciones de calidad ambiental}

La declaración de un parque nacional es etiqueta de calidad, de prestigio, algo así como la denominación de origen de los alimentos. Como se expone en Alba (1993) el ciudadano medio asocia de manera inmediata la expresión «parque nacional» con ideas positivas, actuando como un factor de atracción por si mismo. Semejante distintivo anuncia un territorio de élite que puede satisfacer el creciente deseo de 
conocimiento y utilización de espacios naturales que demanda una sociedad económica cada vez más urbana y terciarizada (Crespo 2006).

Sajambre y Valdeón conservan valores muy apreciados por la población residente en las ciudades que están propiciando un desarrollo de su sector servicios. Atender esta demanda de naturaleza inducida por la existencia del parque puede conllevar una mejora de la dotación básica de equipamientos del área geográfica afectada, pues la institución declarante, en este caso, la administración central, se compromete a invertir en el territorio. Las menciones de calidad ambiental impulsan la construcción de infraestructuras de recepción y acogida de visitantes aptas para divulgar los valores ambientales de la zona. Sin embargo esta teoría, que ha sido bien aplicada en Asturias y Cantabria, no se ha materializado aún en León. Una constatación real de las debilidades relativas a la falta de apoyo local a las figuras de protección.

El parque nacional lleva más de una década anunciando la construcción de dos centros de recepción de visitantes en Posada y Oseja, existiendo incluso partida presupuestaria para tal cometido. A día de hoy todavía son meros proyectos. Una agria realidad que empaña las bondades inherentes a distinguir unos valles de montaña por su interés ambiental. Lo mismo ocurre con los aparcamientos disuasorios que iban a construirse en ambos municipios, anunciados incluso al mismo tiempo que los centros de interpretación. Continúan siendo proyectos.

De esta forma resulta difícil atraer turismo a los Picos leoneses, que actúan en franca desventaja respecto a los Picos asturianos y cantabros por encontrarse anclada la dotación de infraestructuras básicas que resultan vitales para el desarrollo turístico. Es innegable que la revalorización del territorio que conlleva la mención parque nacional se ve lastrada por semejantes actuaciones institucionales. Urge pasar de las intenciones a los hechos. Las promesas incumplidas no hacen más que perjudicar el papel del parque como elemento dinamizador.

Se trasmite una sensación de inmovilismo, de parálisis, que termina generando efectos opuestos a la idea de beneficio que conlleva una figura de protección como la analizada. No así en actuaciones de rango menor, aunque no menos importantes, que tienen por objeto la concesión de ayudas financieras para la rehabilitación de viviendas y otra clase de inmuebles de los municipios afectados. Medidas promovidas por el parque nacional que a la vez que mejoran la calidad de vida de los 
residentes logran elevar la estética de los pueblos, con el consiguiente efecto positivo para el turismo.

A modo de referencia, la renovación de tejados de fibrocemento (uralita) por teja o el revocado de fachadas con piedra y otros materiales autóctonos de la comarca, léase madera y piedra. Acciones que, al erradicar el feismo que anula la tradición constructiva de la zona, sólo han acarreado ventajas para la percepción de Sajambre y Valdeón. A este respecto sería conveniente una revisión del sistema de adjudicación de ayudas, que actualmente ya gestiona la Junta de Castilla y León, con el fin de que la inversión en mejora de inmuebles se dirija principalmente a los residentes reales en lugar de a los propietarios en general. Se premiaría, de alguna manera, la residencia efectiva a la vez que se evitarían fenómenos de signo especulativo como la revalorización, con fondos públicos, de inmuebles no habitados convertidos en segundas residencias ocasionales, con el efecto que ello introduce en un mercado inmobiliario local ya distorsionado por no residir buena parte de los propietarios en ambos municipios. Sin embargo, y sin desmerecer esta clase de apoyos, falta el impulso de un verdadero plan estrella en materia de equipamientos acorde con la singularidad de estas montañas.

\section{Rentabilidad laboral de las figuras de protección}

Siguiendo a Casas (2008), aún cuando la declaración de un espacio protegido no se puede vincular directamente con un determinado impulso económico, ni aspirar a que el beneficio económico sea un fin intrínseco de la declaración, lo cierto es que el nacimiento de un parque nacional siempre conlleva la creación de puestos de trabajo vinculados a las tareas y servicios técnicos de guardería, guías, parque móvil, administración y otras categorías profesionales análogas. Por lógica, la comunidad residente en el espacio protegido es la más seria candidata a ocupar este tipo de plazas, persiguiéndose con esta medida integrar a los habitantes en las actividades desarrolladas por el parque nacional. De hecho esta clase de empleo puede contribuir, y de manera muy eficaz, al objetivo de fijar población en los entornos rurales. En el caso de Sajambre y Valdeón el parque tiene todas las opciones para constituirse en la primera empresa de ambos valles. Entre plantilla fija (funcionarios) y eventual (personal laboral), que casi se duplica en plena campaña de actividad (meses de junio a octubre), crea una ocupación directa de 38 personas con el siguiente desglose de funciones y temporalidad. 
Cuadro 2. Plantilla del parque nacional de los Picos de Europa en Sajambre y Valdeón

\begin{tabular}{|l|c|l|}
\hline Categoría profesional & Número & Temporalidad \\
\hline Agente Medioambiental & 2 & 12 meses \\
\hline Guardas & 8 & 12 meses \\
\hline Conductores & 2 & 12 meses \\
\hline Administrativos & 3 & 12 meses \\
\hline Capataces de obras & 2 & 12 meses \\
\hline Peones & 4 & 12 meses \\
\hline Guía interpretador & 1 & 12 meses \\
\hline Guía interpretador & 3 & 10 meses $\left(^{*}\right)$ \\
\hline Guía interpretador & 1 & 3 meses $\left(^{*}\right)$ \\
\hline Operarios cuadrilla de incendios & 8 & $4-6$ meses $\left(^{*}\right)$ \\
\hline Operarios recogida de basuras & 4 & $3-8$ meses $\left(^{*}\right)$ \\
\hline Total & $\mathbf{3 8}$ & \\
\hline
\end{tabular}

Fuente: Elaboración propia.

Las categorías profesionales marcadas con asterisco, un total de 16, son personal contratado a través de Tragsa, empresa intermediaria calificada como "medios propios del Estado". El resto, un total de 22, son funcionarios o personal laboral del actual Ministerio de Medio Ambiente y Medio Rural y Marino. Esta sería la rentabilidad de la ocupación generada por la protección de la naturaleza, concebida desde esta perspectiva como una ramificación de los dividendos que puede reportar el capital natural de un territorio. Por otra parte, esta oferta de empleo verde auspiciada por organismo públicos relacionados con la conservación y la tutela del medio ambiente es el complemento idóneo de los puestos de trabajo que inducen las actividades turísticas, ganaderas y agroalimentarias, contribuyendo así a pluralizar el origen de las rentas surgidas en el área protegida. 
Matriz DAFO de los Picos de Europa de León

\begin{tabular}{|c|c|}
\hline DEBILIDADES & AMENAZAS \\
\hline $\begin{array}{l}\text { - Crisis del modelo económico tradicional } \\
\text { - Déficit de recursos humanos } \\
\text { - Falta de apoyo local a las figuras de protección }\end{array}$ & $\begin{array}{l}\text { - Deficiencias en la gestión del espacio natural } \\
\text { - Peligro de la sobreexplotación turística } \\
\text { - Déficit de educación ambiental por parte de los } \\
\text { visitantes } \\
\text { - Uso impropio de la denominación Picos de } \\
\text { Europa }\end{array}$ \\
\hline FORTALEZAS & OPORTUNIDADES \\
\hline $\begin{array}{l}\text { - Calidad del patrimonio natural } \\
\text { - Único parque nacional peninsular del noroeste } \\
\text { de España } \\
\text { - Disposición de atractivos no vinculados al } \\
\text { medio ambiente }\end{array}$ & $\begin{array}{l}\text { - Menciones de calidad ambiental } \\
\text { - Incremento de la demanda social de lugares } \\
\text { naturales } \\
\text { - Rentabilidad laboral de la protección ambiental }\end{array}$ \\
\hline
\end{tabular}

\section{CONCLUSIONES}

La matriz DAFO enseña el camino para mejorar la realidad poco halagüeña de la vertiente leonesa de los Picos de Europa: actuar sobre fortalezas y oportunidades con el fin de contrarrestar debilidades y amenazas. Este enclave de la Cordillera Cantábrica no tiene por qué ser un territorio empobrecido, inerte o sin vida. Tiene a su favor un potencial endógeno desaprovechado. Patrimonio natural y cultural, en función de las excelentes posibilidades que encierran ambos, dan, hasta la fecha, un rendimiento de perfil bajo, insuficiente para combatir la transformación del clásico medio de vida agroganadero, hoy por hoy el principal problema que afronta la comarca.

Romper la imagen de pueblos que ven reducir su censo a favor de las capitales urbanas obliga a redefinir el patrón de crecimiento económico. Sería necesario recuperar el sector primario en Sajambre y Valdeón. El rescate de la ganadería extensiva con la posterior transformación de las producciones cárnicas y lácteas diversificaría una generación de rentas muy dependiente de un sector servicios estacional definido por el binomio turismo-parque nacional, a la vez que beneficiaría a la riqueza medioambiental de ambos valles.

De cara a la explotación económica del turismo resulta decisivo corregir graves carencias relativas a la promoción del espacio 
natural. Sajambre y Valdeón, a tenor del pequeño porcentaje de visitas que reciben, resultan, pese a su indudable atractivo, poco conocidos. Hay un serio problema de marketing de cara a combatir la excesiva identificación de los Picos de Europa con Asturias y Cantabria. En una sociedad mediática como la actual lo que no se promociona no existe, no siendo ajeno a tan bajo nivel de afluencia de visitantes el retraso secular en la dotación de infraestructuras y equipamientos turísticos. Desidia y posiciones enfrentadas, cuando no erráticas, provenientes de dos administraciones, central y autonómica, privan a León de rentabilizar, en mayor medida, un capital natural tan emblemático del noroeste peninsular como son los Picos de Europa.

Es presumible que la agregación de las tres ramas de actividad, primaria, secundaria y terciaria, configuraría un modelo económico más equilibrado capaz de conseguir un balance demográfico robusto, de verdadero signo positivo. Actualmente no es así por la ausencia de este efecto suma. El sector servicios reemplazó al sector agroganadero y parece conveniente un cierto contrapeso en el trasvase sectorial del empleo.

\section{BIBLIOGRAFÍA}

ALBA, J. (1993) "Los parques nacionales. Motor de desarrollo rural", El Boletín. Ministerio de Agricultura, Pesca y Alimentación, abril, pp.4853.

CASAS, J. (1998) "Los Picos de Europa como parque nacional. Ejemplo de una encrucijada", Abaco, 17-18, pp. 27-38.

- (2008) "Una aportación a la estimación de los efectos socioeconómicos de la conservación del patrimonio natural", Ambienta, abril, pp. 44-53.

CRESPO, E. (2006) "La red de parques nacionales en el proyecto turístico español", Estudios Turísticos, 169, pp. 51-76.

GarcíA, A. (1999) "Actividades humanas en la zona leonesa de los Picos de Europa", Programa de Formación Ambiental, Ministerio de Medio Ambiente y Fondo Social Europeo, pp. 1-14.

LAGo, J. (2007) "Turismo académico en espacios naturales protegidos". Uso sostenible y conservación en la Cordillera Cantábrica ¿Es posible un 
acuerdo?. Oviedo: Plataforma para la Defensa de la Cordillera Cantábrica, pp.99-104.

- (2008) "Presencia humana y hábitat socioeconómico en Picos de Europa. Consideraciones acerca de los parques nacionales", B. FUERTES MARCOS (coord.) Inventario y valoración de fauna cantábrica II, ponencias técnicas de los cursos del Aula Picos de Europa 2003-2006, Universidad de León, pp. 407-418.

SeVILLA, L. (1997) "Bases para un desarrollo turístico de la montaña de Riaño y Picos de Europa (Sajambre y Valdeón)", VII Curso de Economía Leonesa, Universidad de León.

TORRES, J.C. (2005) "El futuro de los parques nacionales: 13 parques para 10 gobiernos", Natura, 252, pp. 38-47.

URZ Asociación para Estudio y Protección de la Naturaleza (1995) "Propuestas de desarrollo turístico para Sajambre y Valdeón", IV Curso de Economía Leonesa "Posibilidades del turismo de montaña en la provincia de León", Universidad de León, pp. 137-160. 